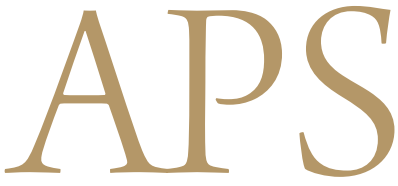

Archives of Plastic Surgery

\title{
Hinged multiperforator-based extended dorsalis pedis adipofascial flap for dorsal foot defects
}

\author{
Magdy A. Abd Al Moktader \\ Department of Plastic Surgery, Faculty of Medicine, Al-Azhar University, Cairo, Egypt
}

Background Adipofascial flaps covered with a skin graft address the challenges involved in reconstructing dorsal foot defects. The purpose of this study was to describe a large adipofascial flap based on the perforators of the dorsalis pedis artery for large foot defects.

Methods Twelve patients aged 5-18 years with large soft tissue defects of the dorsal foot due to trauma were treated with an extended dorsalis pedis adipofascial flap from May 2016 to December 2018. The flap was elevated from the non-injured half of the dorsum of the foot. Its length was increased by fascial extension from the medial or lateral foot fascia to the plantar fascia to cover the defect. All perforators of the dorsalis pedis artery were preserved to increase flap viability. The dorsalis pedis artery and its branches were kept intact.

Results The right foot was affected in 10 patients, and the left foot in two patients. All flaps survived, providing an adequate contour and durable coverage with a thin flap. Follow-up lasted up to 2 years, and patients were satisfied with the results. They were able to wear shoes. Donor-site morbidity was negligible. Two cases each of partial skin graft loss and superficial necrosis at the tip of the donor cutaneous flap occurred and were healed by a dressing.

Conclusions The hinged multiperforator-based extended dorsalis pedis adipofascial flap described herein is a suitable method for reconstructing dorsal foot defects, as it provides optimal functional and aesthetic outcomes with minimal donor site morbidity.

Keywords Foot injuries / Dorsalis pedis flap / Perforator flaps / Dorsal foot soft tissue defects

\author{
Correspondence: \\ Magdy A. Abd Al Moktader \\ Department of Plastic Surgery, Faculty \\ of Medicine, Al-Azhar University, \\ Mokhyam Daem street, Cairo 11884, \\ Egypt \\ Tel: $+20-473253132$ \\ Fax: $+20-473253132$ \\ E-mail: \\ magdyabdelmoktader@azhar.edu.eg
}

I would like to acknowledge the Plastic and Reconstructive Surgery Departments at Al-Hussein University Hospital and Dr. Mahmoud Aldoseky, a specialist in plastic surgery, for drawing a schematic illustration.

\section{INTRODUCTION}

The foot is important because it supports the body and provides a stable interface between the ground and the body. Its function can be affected by trauma, which is the most common cause of soft-tissue defects of the foot, and the method of reconstruction chosen also has functional implications $[1,2]$. Poor vascularity, relatively tight skin, and a bony prominence at the dorsum of the foot make proper reconstruction difficult.

Many techniques have been described for the reconstruction of dorsal foot defects, such as free tissue transfer, reversed pedicle anterior tibial and posterior tibial fasciocutaneous flaps, extensor digitorum brevis muscle flaps, dorsalis pedis artery flaps, reversed soleus muscle flaps, and fasciocutaneous and adipofascial flaps. All of these techniques have specific advantages and disadvantages [3-8].

Local adipofascial flaps have several advantages for the reconstruction of dorsal foot defects. One advantage is that the donor tissue has the same origin, meaning that the donor and recipient tissues have similar characteristics and a stable and reliable vas- 
cular anatomy. Better functional and aesthetic results are achieved through the thinness and reliability of these flaps, with minimal donor site morbidity $[9,10]$.

In this study, the dorsalis pedis adipofascial flap was modified by extending it to include more fascia either from the lateral or the medial side of the foot to the plantar fascia as a continuation to the dorsal fascia of the foot. Simultaneously, the continuity of the dorsalis pedis artery and its perforators to the deep structures was preserved. This was achieved by turning the flap to the other side, using all perforators of the dorsalis pedis artery as the source of the blood supply. The dorsalis pedis artery represented the arc of rotation of the flap. As such, rotating the flap was much like turning a page of a book, while keeping the continuity of the dorsalis pedis artery and its deep communications with the plantar aspect intact.

The dorsalis pedis artery is a continuation of the anterior tibial artery. It ends as the first dorsal metatarsal artery (FDMA) and supplies blood to the dorsal skin, muscles, and bones of the foot. It also provides plantar branches that communicate with the branches of the medial and lateral plantar artery. Through its distal artery, the FDMA communicates with the plantar arterial network. The dorsalis pedis artery consistently provides five to seven perforators to the skin, which emerge perpendicularly from the dorsalis pedis artery at $0.4-$ to $0.5-\mathrm{cm}$ intervals between the extensor retinaculum and the FDMA. These perforators penetrate the deep fascia to supply the skin and fascia. The two most distal cutaneous perforators from the dorsalis pedis artery are found at an average distance of $4.0 \mathrm{~cm}$ (range, $2.8-4.5 \mathrm{~cm}$ ) and $6.0 \mathrm{~cm}$ (range, $5.0-7.3 \mathrm{~cm}$ ) proximal to the metatarsophalangeal joint [11-13].

\section{METHODS}

\section{Design of the study}

Twelve patients aged 5-18 years with post-traumatic soft tissue defects of the dorsal foot and ankle 9-15 cm in length and 5-8 $\mathrm{cm}$ in width were treated with an extended dorsalis pedis multiperforator adipofascial flap that included all perforators of the dorsalis pedis artery. Written consent was obtained from the patients or their parents. The patients underwent surgery from 0 to 10 days after being injured. All cases were carried out and documented at the Department of Plastic and Reconstructive Surgery, Al-Hussein University Hospital, Al-Azhar Faculty of Medicine from May 2016 to December 2018.

\section{Inclusion criteria}

If the defect was on one side of the dorsum of the foot (either the medial or the lateral side), the dorsalis pedis artery must have been intact and palpable. The other uninjured side of the foot, representing the donor side for the fascial flap, was required to be healthy, with no shearing or contusion.

\section{Surgical techniques and flap design}

Fig. 1 illustrates the design of the fascial flap on the lateral aspect of the foot, which was extended to include the continuation of the fascia from the plantar aspect. Fig. 2 shows the design of the fascial flap on the medial aspect of the foot, which was extended to include the continuation of the fascia from the plantar aspect. The dissection was conducted under a tourniquet and with a magnifying loupe. Skin incisions were performed on the edge of the original wound, and could be extended distally or proximally in an S-shaped manner when required. The dissection level for the skin flap was just under the dermis, leaving a fat lobule to preserve the subdermal plexus to the skin. Fat lobules were also preserved on the fascial flap to maintain its vascularity. The dissection was extended to include the plantar extension of the dorsal fascia either medially or laterally. The flap was $1-2 \mathrm{~cm}$ wider than the defect. The fascial flap was then elevated with preservation of the tendon and its paratenon. The dissection proceeded

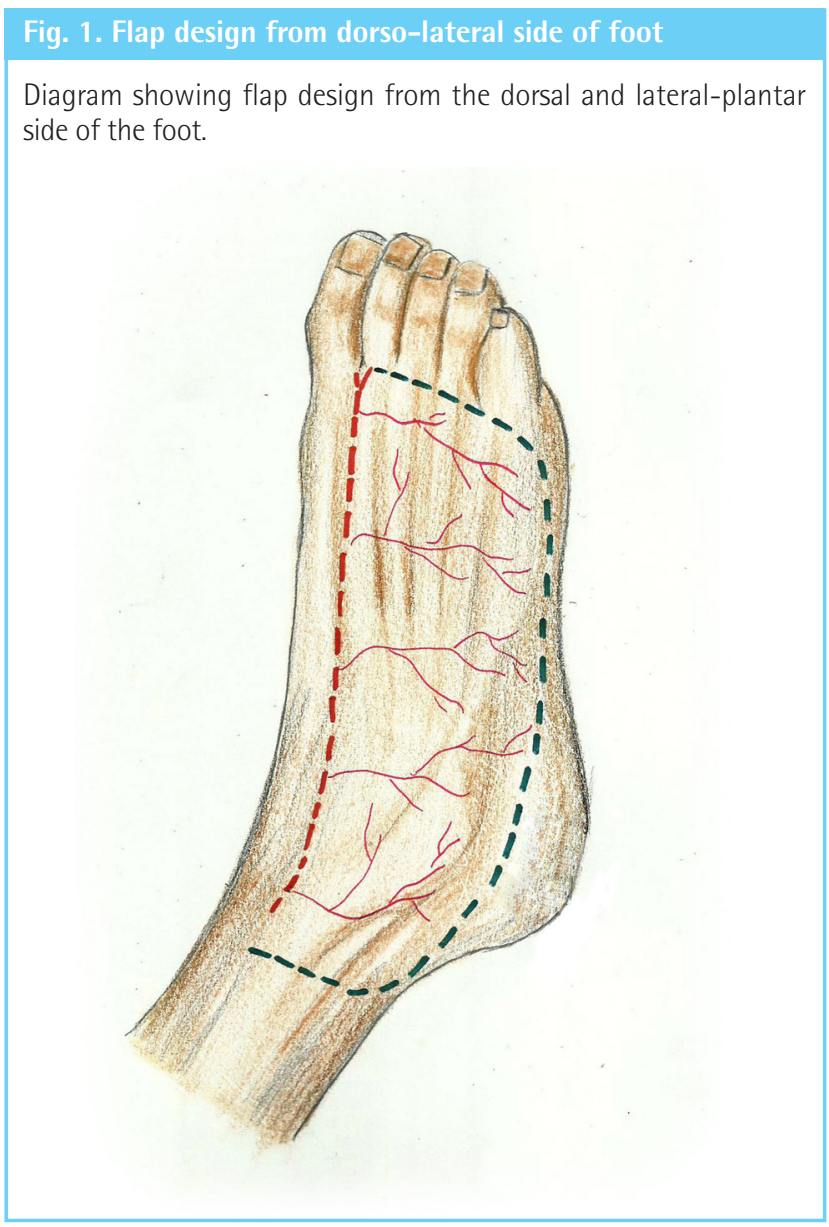




\section{Fig. 2. Flap design from dorso-medio-plantar side of foot}

Diagram showing flap design from the dorsal and medial-plantar side of the foot.

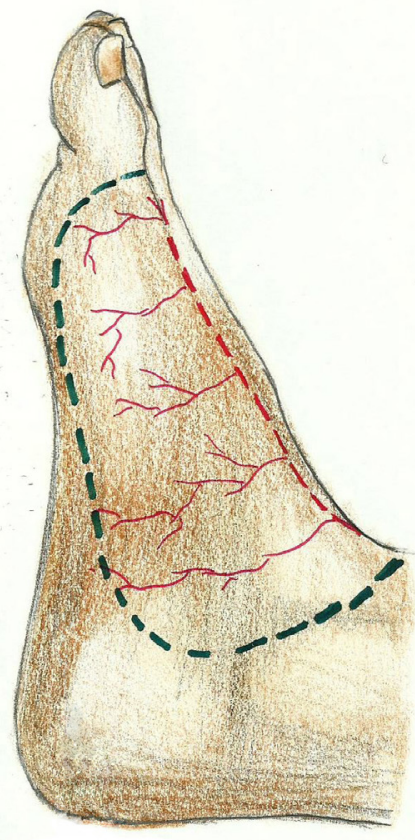

from the lateral or medial aspect toward the artery; at the level of the artery, all perforators of the fascia were preserved. The dorsalis pedis artery was also preserved. The fascial attachment to the artery was released, enabling it to be turned to the opposite side while making sure that all branches and arterial connections with the plantar aspect were intact (Figs. 3, 4, 5C, 6B). The fascial flap was then turned toward the defect, just like turning the pages of a book. The main arc of rotation was the dorsalis pedis artery itself. The fascial flap was then sutured to the recipient site with absorbable 4/0 sutures (Figs. 5D, 6C). A split skin graft was harvested from the thigh and applied over the fascial flap. The average flap length was $13 \mathrm{~cm}$ (range, 9-15 cm), while the average flap width was $6 \mathrm{~cm}$ (range, $5-8 \mathrm{~cm}$ ).

\section{RESULTS}

Twelve flaps were performed in 12 patients, who ranged in age from 5 to 18 years. The injuries were caused by trauma, and affected the right foot in 10 patients and the left foot in two patients. In seven patients, the injuries were on the lateral aspect of the foot, while in five patients, the medial aspect was affected. The patients were treated with an extended dorsalis pedis multiperforator adipofascial flap that turned on all perforators of the

\section{Fig. 3. Showing a fascial flap on lateral side}

Diagram showing a fascial flap elevated from the dorsal aspect of the foot with its fascial extension on the lateral-plantar side to cover a defect on the medial aspect.

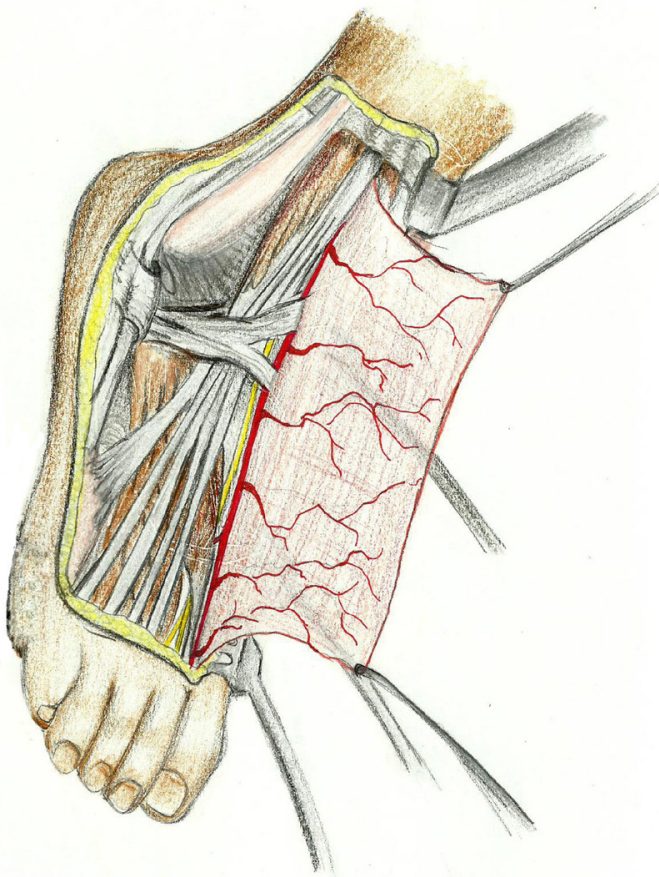

Fig. 4. Showing a fascial flap on medial side

Diagram showing a fascial flap elevated from the dorsal aspect of the foot with its fascial extension on the medial-plantar side to cover a defect on the lateral aspect.

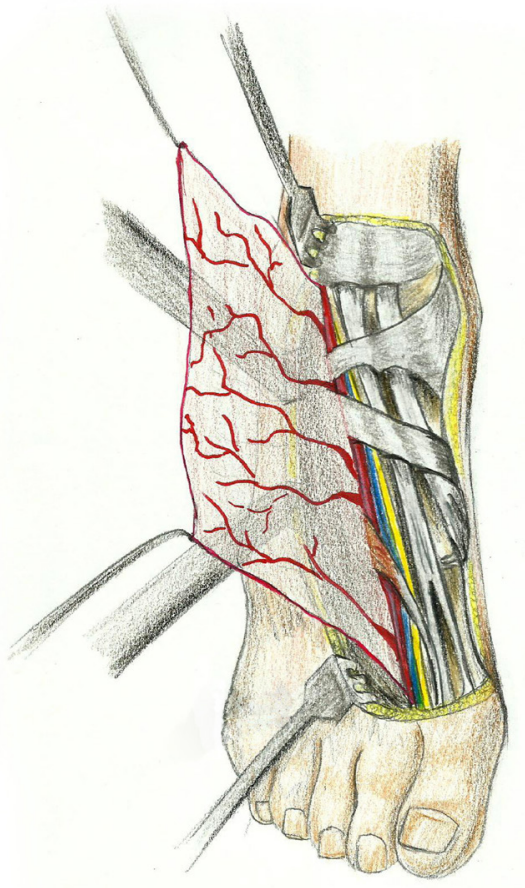




\section{Fig. 5. Clinical photographs of patient No. 2}

A 5-year-old child presented with a crush injury to the lateral aspect of the left foot with exposed bone and lost tendon (patient No. 2). The defect was reconstructed with an extended dorsalis pedis adipofascial flap from the dorsomedial fascia that was extended to include the plantar fascia of the foot and covered by a skin graft. (A) Preoperative photograph of the defect. (B) Preoperative photograph of the donor site. (C) Intraoperative photograph of elevation of the fascial flap. (D) Intraoperative photograph of the flap sutured to the recipient site. (E) One-month postoperative photograph of the recipient side. (F) One-month postoperative photograph of the donor site.
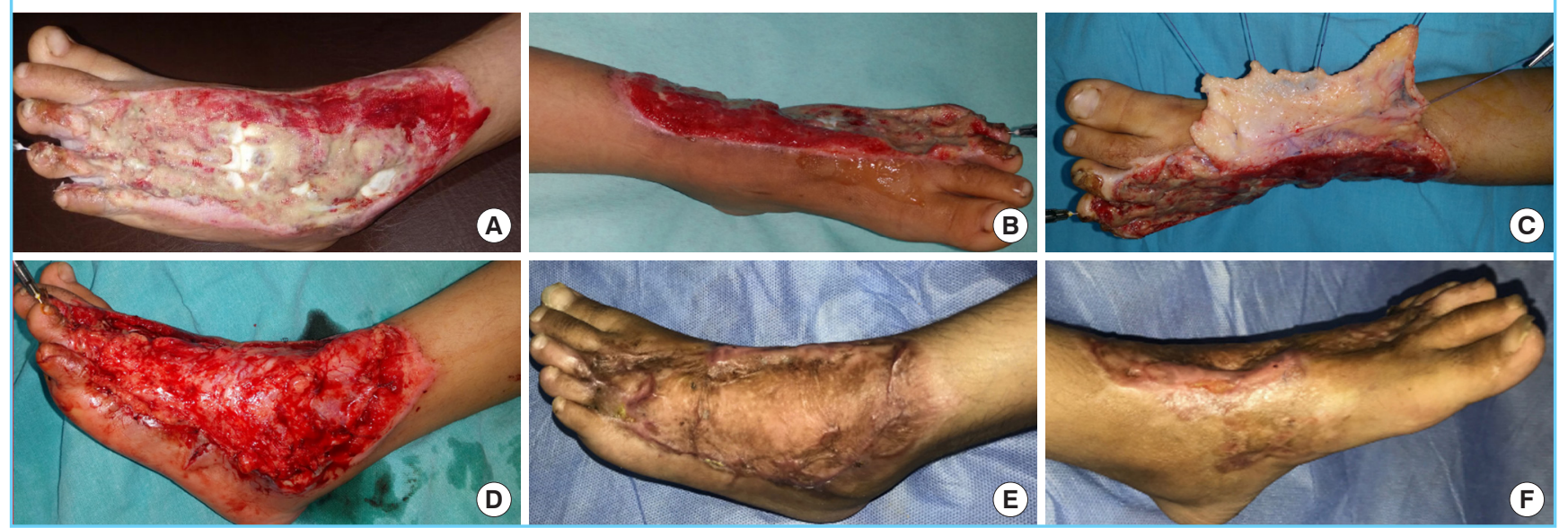

\section{Fig. 6. Clinical photographs of patient No. 4}

A 10-year-old child presented with a crush injury to the dorsomedial aspect of the right foot with exposed bone (patient No. 4). The defect was reconstructed with an extended dorsalis pedis adipofascial flap from the dorsolateral aspect in continuity with plantar fascial extension, covered by a skin graft. (A) Preoperative photograph. (B) Intraoperative view with the flap elevated. (C) Intraoperative photograph of the flap sutured to the recipient site. (D) One-month postoperative photograph of the donor site. (E) One-month postoperative photograph of the recipient site.
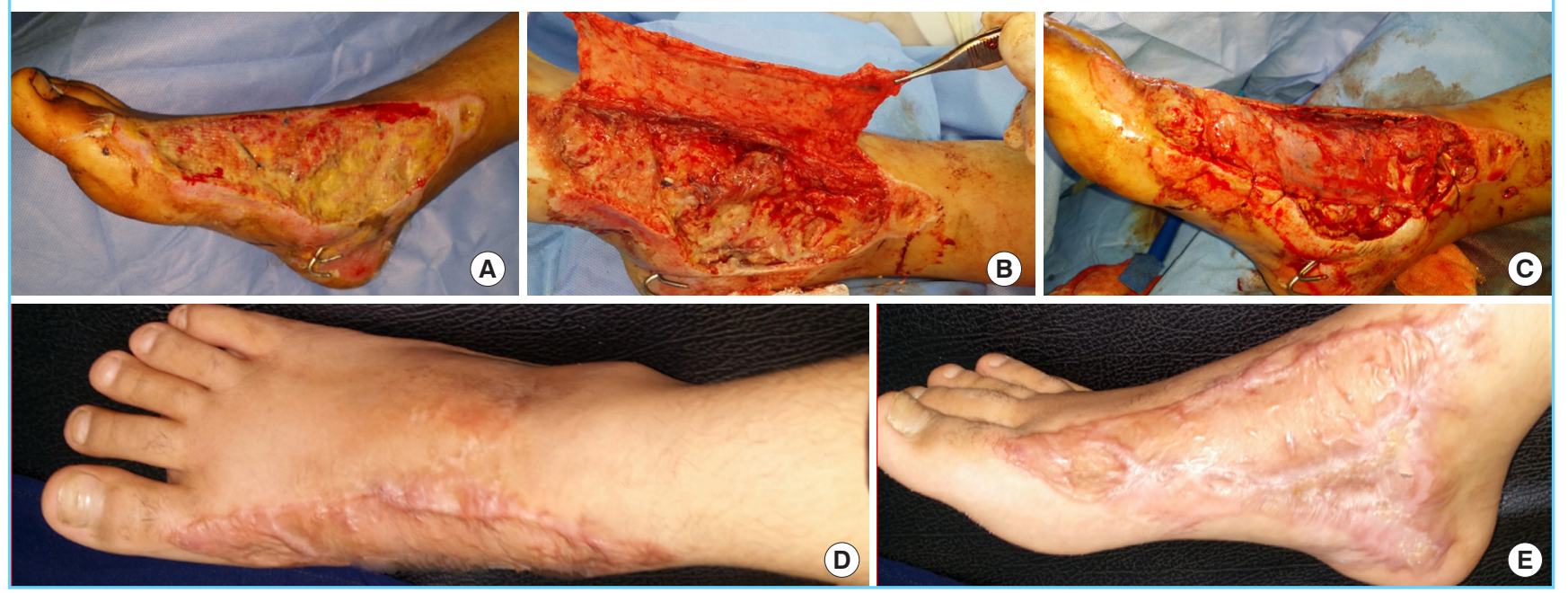

dorsalis pedis artery (Table 1).

Flap viability, stable coverage (especially of the bony prominence of the foot), bulkiness of the flap, ability to wear shoes, and donor site morbidity were assessed as outcomes.

All flaps survived and provided an adequate foot contour for wearing ordinary shoes. There were two cases of partial skin graft loss on the fascial flap that were healed using a dressing. In two patients, necrosis affected $1 \mathrm{~cm}$ of the tip of the donor site skin flaps, and these cases healed by dressing.

Due to the durable and stable coverage and thinness of the flaps, the results were satisfactory for both the patients and the surgeon. During a follow-up period of up to 2 years, the patients did not experience any problems with normal daily activity and were able to wear shoes. The donor site was negligibly affected, with intact skin and minimal complications, as shown in Figs. 5 and 6.

\section{DISCUSSION}

The advantages of immediate soft tissue coverage of exposed 


\section{Table 1. Demographic and clinical characteristics of the patient}

\begin{tabular}{|c|c|c|c|c|c|c|c|c|c|}
\hline $\begin{array}{l}\text { Patient } \\
\text { No. }\end{array}$ & $\begin{array}{c}\text { Age } \\
(y r) / \\
\text { sex }\end{array}$ & $\begin{array}{l}\text { Type of injury } \\
\text { and site }\end{array}$ & $\begin{array}{l}\text { Defect } \\
\text { size } \\
(\mathrm{cm})\end{array}$ & $\begin{array}{l}\text { Time of } \\
\text { surgery } \\
\text { after } \\
\text { trauma } \\
\text { (day) }\end{array}$ & $\begin{array}{l}\text { Previous } \\
\text { procedure } \\
\text { performed }\end{array}$ & $\begin{array}{l}\text { Flap } \\
\text { size } \\
(\mathrm{cm})\end{array}$ & Affected structures & $\begin{array}{l}\text { Follow-up } \\
\text { (mon) }\end{array}$ & Complications \\
\hline 1 & $7 / M$ & Rt. foot, lateral aspect & $10 \times 5$ & 2 & Dressing & $12 \times 7$ & Lost skin and tendons & 6 & $\begin{array}{l}\text { Partial graft loss, healed } \\
\text { by dressing }\end{array}$ \\
\hline 2 & $5 / F$ & Lt. foot, medial aspect & $12 \times 5$ & 10 & Debridement & $14 \times 6$ & $\begin{array}{l}\text { Lost skin and tendons with bone } \\
\text { exposure }\end{array}$ & 3 & None \\
\hline 3 & $15 / M$ & Rt. foot, medial aspect & $9 \times 6$ & 0 & - & $11 \times 7$ & $\begin{array}{l}\text { Lost skin and tendons with bone } \\
\text { exposure }\end{array}$ & 3 & None \\
\hline 4 & $10 / M$ & Rt. foot, lateral aspect & $12 \times 7$ & 8 & Debridement & $14 \times 8$ & Lost skin and exposed tendons & 5 & None \\
\hline 5 & $13 / F$ & Rt. foot, medial aspect & $14 \times 6$ & 5 & Dressing & $15 \times 8$ & $\begin{array}{l}\text { Lost skin and tendons with } \\
\text { metatarsal fractures }\end{array}$ & 2 & None \\
\hline 6 & 9/M & Rt. foot, lateral aspect & $13 \times 6$ & 4 & Dressing & $15 \times 8$ & Lost skin and tendon exposure & 4 & None \\
\hline 7 & $11 / M$ & Rt. foot, medial aspect & $10 \times 7$ & 7 & Dressing & $12 \times 8$ & Lost skin and tendon exposure & 1 & $\begin{array}{l}\text { Donor-site edge necrosis } \\
\text { healed by dressing }\end{array}$ \\
\hline 8 & $12 / M$ & Rt. foot, lateral aspect & $15 \times 7$ & 3 & Dressing & $15 \times 8$ & $\begin{array}{l}\text { Lost skin and tendons with } \\
\text { metatarsal fracture }\end{array}$ & 2 & None \\
\hline 9 & $8 / \mathrm{M}$ & Rt. foot, medial aspect & $12 \times 6$ & 6 & Dressing & $15 \times 8$ & Lost skin and tendons & 2 & None \\
\hline 10 & $14 / F$ & Rt. foot, lateral aspect & $15 \times 6$ & 9 & Debridement & $15 \times 8$ & Lost skin and tendons & 1 & $\begin{array}{l}\text { Donor-site edge necrosis } \\
\text { healed by dressing }\end{array}$ \\
\hline 11 & $10 / M$ & Lt. foot, lateral aspect & $13 \times 6$ & 6 & Dressing & $14 \times 7$ & Lost skin and tendon exposure & 1 & None \\
\hline 12 & $7 / \mathrm{M}$ & Rt. foot, lateral aspect & $14 \times 7$ & 4 & Dressing & $15 \times 8$ & Lost skin and tendons & 1 & $\begin{array}{l}\text { Partial graft loss, healed } \\
\text { by dressing }\end{array}$ \\
\hline
\end{tabular}

bones, tendons, nerves, vessels, or osteointegrated implants have been documented in many studies $[14,15]$. The choice of coverage depends on the size, site, shape, and type of the defect. Free flaps are being increasingly used to cover defects of the foot and ankle; however, in comparison to pedicle flaps, microsurgery requires special surgical expertise, a longer operating time, and more aggressive monitoring $[3,16]$.

An adipofascial turnover flap for dorsal foot defects was found to be highly reliable, but with limitations regarding the size of the defect, as the ratio of the base area to the flap area ranged from 1:3.0 to 1:4.3 [9]. The dorsalis pedis myofascial flap supplied by the dorsalis pedis artery is a useful option for larger defects, but its primary disadvantage is that the main artery is sacrificed [17].

Reverse-flow flaps from the lower leg, including anterior tibial flaps [18], posterior tibial fasciocutaneous flaps $[5,19,20]$, and peritoneal flaps [21], provide versatile coverage for dorsal foot defects, but they also have the disadvantage of sacrificing a major artery. Local muscle flaps in the foot and leg play a role in the coverage of foot defects $[22,23]$, but they have a limited arc of rotation and are only applicable for small defects. Russo et al. [11] used the dorsalis pedis adipofascial flap on a distal perforator of the dorsalis pedis artery to cover toes and metatarsal defects, but it was limited to more proximal foot defects. In an ana- tomical and clinical study, El-Khatib [13] used the dorsalis pedis adipofascial flap on a proximal perforator of the dorsalis pedis artery. However, its length and arc of rotation were limited, especially for distal foot defects on medial or lateral aspects.

This study introduces a new modification to the dorsalis pedis adipofascial flap, in which the width of the flap was increased by extending the dorsal fascia of the foot to include the fascia in continuity with the plantar aspect (medial-plantar or lateralplantar) based on the preservation of all perforators of the dorsalis pedis artery to augment its blood supply. A further modification was the arc of rotation, which was based on the main dorsalis pedis artery, thus allowing it to reach any defect in the foot-either proximally or distally—even in the toes, with preservation of the dorsalis pedis artery and its deep and plantar communication.

The extended dorsalis pedis adipofascial flap was rotated into the defect by simply turning it into the defect over the dorsalis pedis artery (arc of rotation), with preservation of the main artery and its deep communication. Moreover, the raw surface of the flap on the recipient site was covered with a split-thickness skin graft in all our cases.

For use of this flap to be suitable, the defect should be on one side of the dorsum of the foot (either medial or lateral to the dorsalis pedis artery), and the artery should be intact. The do- 
nor side for the fascial flap should be healthy, with no shearing or contusion. Furthermore, the extension of the fascia requires meticulous dissection and patience to avoid injuring the overlying cutaneous flap. Therefore, it is unsuitable for central dorsal defects, especially those affecting the area of the artery, as well as run-over accidents associated with degloving injuries to the foot skin.

Adipofascial flaps are thin and pliable and can be easily brought to the defect, and the donor area can be closed primarily. The hinged multiperforator-based extended dorsalis pedis adipofascial flap covered with a skin graft, with preservation of the main dorsalis pedis artery, is a suitable method for reconstructing dorsal foot defects, as it provides optimum functional and aesthetic outcomes with minimal donor site morbidity.

\section{NOTES}

\section{Conflict of interest}

No potential conflict of interest relevant to this article was reported.

\section{Ethical approval}

The study was approved by the local ethical committee of AlAzhar (approval No. 0000028/16) and performed in accordance with the principles of the Declaration of Helsinki. Written informed consents were obtained.

\section{Patient consent}

The patients provided written informed consent for the publication and the use of their images.

\section{ORCID}

Magdy A. Abd Al Moktader

$$
\text { https://orcid.org/0000-0001-5506-7796 }
$$

\section{REFERENCES}

1. Dhilon MS, Aggarwal S, Dhatt S, et al. Epidemiological pattern of foot injuries in india: preliminary assessment of data from a tertiary hospital. J Postgrad Med Edu Res 2012;46: 144-7.

2. Al-Qattan MM. Car-tyre friction injuries of the foot in children. Burns 2000;26:399-408.

3. Nuzumlali E, Gurbuz C, Kantarci U, et al. Moving car-tire injuries of the foot: reconstruction with microvascular free flaps. J Reconstr Microsurg 1996; 12:297-302.

4. Wee JT. Reconstruction of the lower leg and foot with the reverse-pedicled anterior tibial flap: preliminary report of a new fasciocutaneous flap. Br J Plast Surg 1986;39:327-37.

5. Hong G, Steffens K, Wang FB. Reconstruction of the lower leg and foot with the reverse pedicled posterior tibial fasciocutaneous flap. Br J Plast Surg 1989;42:512-6.

6. Gahhos FN, Jaquith M, Hidalgo R. The extended digitorum brevis muscle flap. Ann Plast Surg 1989;23:255-62.

7. Satoh K, Sakai M, Hiromatsu N, et al. Heel and foot reconstruction using reverse-flow posterior tibial flap. Ann Plast Surg 1990;24:318-27.

8. Liu K, Li Z, Lin Y, et al. The reverse-flow posterior tibial artery island flap: anatomic study and 72 clinical cases. Plast Reconstr Surg 1990;86:312-6.

9. Lai CS, Lin SD, Yang CC, et al. Adipofascial turn-over flap for reconstruction of the dorsum of the foot. Br J Plast Surg 1991;44:170-4.

10. Suliman MT. Distally based adipofascial flaps for dorsal foot and ankle soft tissue defects. J Foot Ankle Surg 2007;46: 464-9.

11. Russo A, Delia G, Casoli V, et al. Dorsalis Pedis Adipofascial Perforator flap for great toe reconstruction: anatomical study and clinical applications. J Plast Reconstr Aesthet Surg 2014;67:550-4.

12. Man D, Acland RD. The microarterial anatomy of the dorsalis pedis flap and its clinical applications. Plast Reconstr Surg 1980;65:419-23.

13. El-Khatib HA. Adipofascial turn-over flap based on perforators of the dorsalis pedis for resurfacing forefoot defects: an anatomic and clinical approach. Plast Reconstr Surg 1998; 102:393-7.

14. Yaremchuk MJ, Brumback RJ, Manson PN, et al. Acute and definitive management of traumatic osteocutaneous defects of the lower extremity. Plast Reconstr Surg 1987;80:1-14.

15. Tropet Y, Garbuio P, Obert L, et al. Emergency management of type IIIB open tibial fractures. Br J Plast Surg 1999;52: 462-70.

16. Chiang YC, Jeng SF, Yeh MC, et al. Free tissue transfer for leg reconstruction in children. Br J Plast Surg 1997;50:33542.

17. Ismail TI. The dorsalis pedis myofascial flap. Plast Reconstr Surg 1990;86:573-6.

18. Morrison WA, Shen TY. Anterior tibial artery flap: anatomy and case report. Br J Plast Surg 1987;40:230-5.

19. Heymans O, Verhelle N, Peters S. The medial adiposofascial flap of the leg: anatomical basis and clinical applications. Plast Reconstr Surg 2005; 115:793-801.

20. Lin SD, Lai CS, Tsai CC, et al. Clinical application of the distally based medial adipofascial flap for soft tissue defects on the lower half of the leg. J Trauma 1995;38:623-9. 
21. Yoshimura M, Imura S, Shimamura K, et al. Peroneal flap for reconstruction in the extremity: preliminary report. Plast Reconstr Surg 1984;74:402-9.

22. Attinger CE, Ducic I, Cooper P, et al. The role of intrinsic muscle flaps of the foot for bone coverage in foot and ankle defects in diabetic and nondiabetic patients. Plast Reconstr Surg 2002;110:1047-54.

23. Arnold PG, Yugueros P, Hanssen AD. Muscle flaps in osteomyelitis of the lower extremity: a 20-year account. Plast Reconstr Surg 1999;104:107-10. 